\title{
Pharmaceutical Development of the Combined Structure of the Tablets "Exkair" from Various Phytocompositions
}

\author{
Galiya Ibadullayeva $^{1}$, Volodimir Grudko ${ }^{2}$, Assyl Boshkayeva ${ }^{1}$, Zuriyadda Sakipova ${ }^{1}$, \\ Talgat Dzalgasbayev ${ }^{1}$, Gulbaram Ustenova ${ }^{1}$, Kaldanay Kozhanova ${ }^{1}$, Nazerke Uristemkhankyzy ${ }^{1}$, \\ Eduard Bissenbaev ${ }^{1}$, Nurgan Tussupova ${ }^{1}$, Sholpan Mulkibayeva ${ }^{1}$, Ilyas Tazabekov ${ }^{1}$ \\ ${ }^{1}$ Pharmaceutical Faculty, Asfendiyarov Kazakh National Medical University, Almaty, Republic of Kazakhstan \\ ${ }^{2}$ Pharmaceutical Faculty, National Pharmaceutical University, Kharkov, Ukraine

\section{Email address:} \\ arujan-d@mail.ru (G. Ibadullayeva),431230@ukr.net (V. Grudko), kenes65@mail.ru (A. Boshkayeva), \\ sakipova@archipelag.kz (Z. Sakipova), talga-94@mail.ru (T. Dzalgasbayev), ustenova@list.ru (G. Ustenova), \\ kaldanay_k@mail.ru (K. Kozhanova), shinibekov29@gmail.com (N. Uristemkhankyzy), bissenbayev1941@mail.ru (E. Bissenbayev), \\ tusupova-n@mail.ru (N. Tussupova),sh_mulkibayeva@mail.ru (S. Mulkibayeva), tazabekovis@qmail.com (I. Tazabekov)
}

\section{To cite this article:}

Galiya Ibadullayeva, Volodimir Grudko, Assyl Boshkayeva, Zuriyadda Sakipova, Talgat Dzalgasbayev, Gulbaram Ustenova, Kaldanay Kozhanova, Nazerke Uristemkhankyzy, Eduard Bissenbaev, Nurgan Tussupova, Sholpan Mulkibayeva, Ilyas Tazabekov. Pharmaceutical Development of the Combined Structure of the Tablets "Exkair" from Various Phytocompositions. Clinical Medicine Research. Vol. 5, No. 3, 2016, pp. 39-44. doi: 10.11648/j.cmr.20160503.15

Received: February 20, 2016; Accepted: April 25, 2016; Published: May 13, 2016

\begin{abstract}
We have received extracts from air-dried raw material of medicinal plants Acorus Calamus and Calendula officinalis in the mode of low-temperature subcritical extraction by liquefied carbon dioxide $\left(\mathrm{CO}_{2}\right)$, the output of which made 0.7 to $0.8 \%$. The content of camphor and $\beta$-pinene in $1 \mathrm{~g}$ of Acorus Calamus extract is not less than $0.1 \%$; the content of carotenoids in terms of $\beta$-carotene in $1 \mathrm{~g}$ of the extract of Calendula officinalis - not less than $0.35 \mathrm{mg} / \mathrm{g}$. We have developed combined pills "Exkair" of the following composition: thick extract of Acorus Calamus rhizomes (0.009 g), thick extract of flowers of Calendula officinalis $(0.005 \mathrm{~g})$; auxiliary substances - ascorbic acid $(0.005 \mathrm{~g})$, calcium stearate $(0.006 \mathrm{~g})$, sugar powder $(0.517 \mathrm{~g})$, aerosil $(0.015 \mathrm{~g})$. The pills underwent a number of physico-chemical testings according to the requirements of the project PAND (Provisional Analytic Normative Document). The content of active substances (carotenoids) in 1 tablet is $0.782 \mathrm{mg}$, camphor and pinene $0.97 \mathrm{mg}$.
\end{abstract}

Keywords: Tablets, $\mathrm{CO}_{2}$-Extracts, Quality Indicators, Camphor, Carotenoids, Acorus Calamus, Calendula Officinalis

\section{Introduction}

The share of preparations on the basis of medicinal vegetable raw materials steadily grows in the market of the modern domestic pharmaceutical market [1, 2, 3]. The widespread use of multi-component of composition of biologically active agents, simultaneous presence of connections of various pharmacological natures that is reflected in the natural mechanism of a range of biological effect $[4,5,6,7,8]$.

To extract a significant group of biologically active substances from medicinal plant raw material was chosen as the technology of carbon dioxide extraction. The Method of processing of raw materials of carbon as dioxide $\left(\mathrm{CO}_{2}\right)$ was chosen from medicinal vegetable raw materials allows drawing in high concentration various lipophilic substances. The technology of application of carbon dioxide extraction has undoubted advantages before traditional ways of extraction [9]: rather small time of extraction, small power consumption, harmlessness of production, the operated selectivity in relation to groups of the biologically active substances (BAS). In receiving extracts by organic solvents [10] the selectivity of extraction of valuable components is not ensured and thermolabile substances of extracts are destroyed while distilling off the solvent.

By researches of last years there was established that obtaining high-qualitative plant extracts is more expedient to use solvents of compressed and liquefied gases. The more 
acceptable solvent for this purpose is liquid carbon dioxide.

This extra agent has a complete affinity to the most important biologically active substances and that allows extraction processing from raw materials at room temperature $\left(18\right.$ to $\left.22^{\circ} \mathrm{C}\right)[11,12,13,14]$.

Thus, the extracts obtained by $\mathrm{CO}_{2}$-extraction, are to be promising phytosubstances, which may be used to produce solid medicinal forms. This is due to the large range of their therapeutical properties because of the content of biologically active substances, low toxicity, broad spectrum of activity and good tolerability. Rational combination of plant extracts with various subsidiary substances allows expanding their therapeutic effects. In addition, using a combination of various medicinal substances of vegetable origin in the complex drugs, you may achieve predictable pharmacological effect $[15,16]$.

The aim of this study was development of the combined structure of tablets on the basis of new phytosubstances of the $\mathrm{CO}_{2}$-extracts received from rhizomes of the Acorus Calamus and flowers of the Calendula officinalis.

In this case, the received carbon dioxide extracts meet the requirements of pharmacopeia purity $[17,18]$ for quality indicators: determination of microbiological purity, authenticity, content of water, heavy metals and quantitative contents. PAND imposes regulatory requirements for safety and quality pills, developed on the basis of carbon dioxide extracts.

\section{Experimental Part}

The spectrophotometry method in the UF region of a range was used for confirmation of authenticity of carotenoids in $\mathrm{CO}_{2}$-extract of the Calendula officinalis and definitions of the maintenance of carotenoids. The absorbing range of the solution prepared for quantitative definition of the examinee of solution in the range from 350 nanometers to 500 nanometers has a maximum at the wavelength $(401 \pm 2$ nanometers) and a plateau from ( $419 \pm 2$ nanometers) to ( $425 \pm 2$ nanometers). The relation of optical density in a maximum at the wavelength ( $401 \pm 2$ nanometers) to optical density at the wavelength ( $422 \pm 2$ nanometers) has to be from 1.00 till 1.15 .

Definition of carotenoids is carried out by method of a thin layer chromatography.

The solution prepared for quantitative definition is used as the examinee of solution.

Standard solution. $0.3600 \beta$-carotene (SS Merck) place in a measured flask with a capacity of $1000 \mathrm{ml}$ dissolve in water $P$, bring solution volume to a tag the same solvent and carefully mix.

On the line of start TLC of the plate Sorbfil (or similar) covered with a layer of silicagel apply in the form of a strip $10 \mu \mathrm{l}$ the studied solution and of standard solution. The plate is dried on air before removal of solvent, placed in the camera with mix of solvents hexane $P$ - ether $P$ (8:2) also chromatographed in the ascending way. When the front of solvents passes $10 \mathrm{~cm}$ from the line of start, a plate take out from the camera and dry on air before removal of vapors of solvents. The plate is processed by $10 \%$ solution of acid phosphomolybdic in ethanol $P$, heat in a drying cabinet at a temperature of $60-80^{\circ} \mathrm{C}$ within $5 \mathrm{~min}$ and viewing through in visible light.

On a chromatogram of the examinee of solution not less than 3 strips of blue color with $\mathrm{R}_{\mathrm{f}} 0.07 ; \mathrm{R}_{\mathrm{f}} 0.18 ; \mathrm{R}_{\mathrm{f}} 0.79$ on a yellow-green background and a strip on the line of start.

Preparation of $1 \%$ alcohol solution of phosphomolybdic acid. 10.0 of acid phosphomolybdic $P$ is placed in a measured flask with a capacity of $100 \mathrm{ml}$, dissolved in $95 \%$ ethanol $P$, bring solution volume the same solvent to the mark and mixed.

Quantitative definition of active ingredients was carried out by methods of a highly effective liquid chromatography.

Carotenoids. Test is carried out by method of the absorptive spectrophotometry in ultra-violet and visible region ( $\mathrm{SPh} \mathrm{RK}$ I, t. 1, 2.2.25).

Examinee solution. $0.2000 \mathrm{~g}$ of the test the $\mathrm{CO}_{2}$-extract transfers to a measured flask with a capacity of $50.0 \mathrm{ml}$, dissolve in $30 \mathrm{ml}$ of the hexane $P$; bring solution to the mark the same solvent and mix.

The received solution is left to full sedimentation of not dissolved particles. A pipette select solution from the center of a measured flask and measure optical density on the spectrophotometer at the wavelength of 450 nanometers in a ditch with thickness of a layer of $10 \mathrm{~mm}$.

Standard solution. $0.36 \mathrm{~g}$ of potassium dichromate $(\mathrm{SPh}$ RK, I, t. 1) place in a measured flask with a capacity of 1000 $\mathrm{ml}$, dissolve in water $P$, bring solution volume to a tag the same solvent and mixed thoroughly.

Measure the optical density of the examinee of solution on the spectrophotometer at the wavelength of 450 nanometers in a ditch with thickness of a layer of $10 \mathrm{~mm}$.

Simultaneously, in the same conditions, the optical density of the standard solution of potassium dichromate in the same conditions, using water $P$ as compensation solution.

Contents of the sum of carotenoids (X) in $\mathrm{mg}$ in terms of $\beta$-carotene, in $1 \mathrm{~g}$ of $\mathrm{CO}_{2}$-extract is calculated by the formula (1):

$$
\mathrm{X}=\left(\mathrm{A}_{0} \cdot 50 \cdot 0.00208\right) /\left(\mathrm{A}_{1} \cdot \mathrm{m}\right)
$$

where $\mathrm{X}$ - maintenance of the sum of carotenoids in $\mathrm{mg}$ terms of $\beta$-carotene, in $1 \mathrm{~g}$ of $\mathrm{CO}_{2}$-extract;

$A_{0}$ - optical density of the examinee of solution;

$A_{1}$ - optical density of the standard solution of potassium dichromate;

0.00208 - quantity $\beta$-carotene in solution (in $\mathrm{mg}$ ) which corresponds on coloring to the standard solution of potassium dichromate;

$\mathrm{m}-$ mass of the extract, $\mathrm{g}$.

The maintenance of the sum of carotenoids in terms of $\beta$ carotene has to be not less than $0.35 \mathrm{mg} / \mathrm{g}$.

Quantitative determination of $\beta$-carotene in tablets $25 \mathrm{ml}$ of hexane was placed in the divided funnel with the capacity of $250 \mathrm{ml}$, then approximately $20 \mathrm{~g}$ (precise linkage) of pounded tablets, $150 \mathrm{ml}$ of water were added and it was 
thoroughly shaken for $3 \mathrm{~min}$, and then allow its settling and separating the aqueous layer.

To the remaining suspension $10 \mathrm{ml}$ of $70 \%$ of ethanol is added and it is shaken for $2 \mathrm{~min}$, and then allowed to settle and after we separate the alcohol layer, but the hexane extract is filtered through paper filter, where $3 \mathrm{~g}$ of anhydrous sodium sulfate is placed in volumetric flask of $25 \mathrm{ml}$. Divided funnel is rinsed with $5 \mathrm{ml}$ of hexane and the filter is washed with this hexane and the volume of solution is adjusted the pointed mark. The optical density of the obtained solution is determined on the spectrophotometer at a wavelength of $450 \mathrm{~nm}$, using hexane as a control solution. Simultaneously we measure the optical density of the standard solution of potassium dichromate. The content of total carotenoids in terms of $\beta$-carotene in $\mathrm{mg}$ is calculated by the formula (2):

$$
\mathrm{X}=\left(\mathrm{D} \cdot \mathrm{V}_{1} \cdot \mathrm{K} \cdot \mathrm{V}_{1 \mathrm{st}} \cdot \mathrm{m}_{\mathrm{av}} \cdot 1000 /\left(\mathrm{D}_{\mathrm{st}} \cdot \mathrm{m} \cdot \mathrm{V}_{2 \mathrm{st}}\right)\right.
$$

where D - optical density of the examinee of solution;

$\mathrm{D}_{\text {st }}$ - optical density of the standard solution 2 of potassium dichromate;

$\mathrm{m}$ - mass of the sample of powdered tablets, $\mathrm{g}$; $\mathrm{m}_{\mathrm{av}}$ - average mass of the tablets, $\mathrm{g}$;

$\mathrm{V}_{1}$ - volume of hexane solution, $\mathrm{ml}$;

$\mathrm{V}_{1 \text { st }}$ - volume of pipettes for dilution of the standard solution 1 of potassium dichromate;

$\mathrm{V}_{2 \mathrm{st}}$ - volume of volumetric flasks for dilutions of the standard solution 2 of potassium dichromate;

$\mathrm{K}-0.00208$ - amount of $\beta$-carotene in $\mathrm{mg}$ in the solution, which corresponds to the color of the standard solution of potassium dichromate.

Standard solution 1 of potassium dichromate. $0.3600 \mathrm{~g}$ (precise linkage) of the standard sample (SS) potassium dichromate dissolved in purified water $P$ in a volumetric flask with a capacity of $1000 \mathrm{ml}$, adjusted to the mark with the same solvent and mix thoroughly. The solution colour corresponds to a solution containing $0.00208 \mathrm{mg}$ of $\beta$ carotene in $1 \mathrm{ml}$.

Standard solution 2 of potassium dichromate. $25 \mathrm{ml}$ of the standard solution of potassium dichromate is placed in a volumetric flask of $50 \mathrm{ml}$ and adjusted to the mark with water purified $P$.

The developed method was the analysis of experimental series of tablets. The data obtained are presented in table 1.

Table 1. The results of quantitative determination of carotenoids in tablets.

\begin{tabular}{llll}
\hline № & The mass of sample, $\mathbf{g}$ & The optical density, $\mathbf{A}$ & The content of the sum of carotenoids in terms of $\boldsymbol{\beta}$-carotene $\mathbf{m g} / \mathbf{t a b l}$ \\
\hline 1 & 20.0051 & 0.250 & 0.779 \\
2 & 20.0003 & 0.253 & 0.788 \\
3 & 19.9984 & 0.248 & 0.773 \\
4 & 20.0082 & 0.260 & 0.810 \\
5 & 19.9965 & 0.245 & 0.763 \\
6 & 20.0098 & 0.251 & 0.782 \\
\hline
\end{tabular}

Notes: $\mathrm{D}_{\mathrm{st}}=0.249 ; \mathrm{m}_{\mathrm{av}}-0.597$.

The obtained data are subjected to statistical analysis and are presented in table 2.

Table 2. Metrological characteristics of the average result, $n=6$.

\begin{tabular}{|c|c|c|c|c|c|c|c|}
\hline Found $\beta$-carotene, mkg & $\mathrm{X}_{\mathrm{av}}, \mathrm{mkg}$ & $S^{2}$ & $\mathbf{S}$ & P, \% & $T(p, v)$ & $\Delta \mathbf{X}_{\text {av. }}$ & $\mathbf{E}_{\mathrm{av}}, \%$ \\
\hline $\begin{array}{l}0.779 \\
0.788 \\
0.773 \\
0.810 \\
0.763 \\
0.782\end{array}$ & 0.782 & $2.54 \times 10^{-4}$ & 0.0159 & 95 & 2.57 & 0.0068 & 0.87 \\
\hline
\end{tabular}

where: $\mathrm{X}_{\mathrm{av}}$ - average value of the sample;

$\mathrm{S}^{2}-$ dispersion;

$\mathrm{S}$ - standard deviation;

$\mathrm{P}$ - confidence coefficient;

$\mathrm{T}(\mathrm{p}, \mathrm{v})$ - tabulated value of criterion Styudents;

$\Delta \mathrm{X}_{\mathrm{av}}$ - half-width of the confidence interval of a single determination;

$\mathrm{E}_{\mathrm{av}}$ - relative uncertainty of the average result.

As can be seen from the presented data, the conditional content of total carotenoids in terms of $\beta$-carotene is 0.782 $\mathrm{mg}$ in terms of the average mass of the tablet.

Identification and quantitative definition of camphor and $\beta$-pinene were carried out by method of a gas chromatography with the ardent and ionization detector. On the chromatograms of the examinee solution received when determining component structure, time of deduction of the main peak has to coincide with time of keeping of peak of camphor on the chromatograms of the standard solution. On the chromatograms of the examinee solution received when determining component structure, time of deduction of the main peak has to coincide with time of keeping of peak $\beta$ pinene on the chromatograms of the standard solution.

1.000 of extract is placed in a measured flask with a capacity of $50 \mathrm{ml}$, dissolved in $96 \%$ alcohol $P$, bring solution volume the same alcohol $P$ to a tag and mix before extract dissolution (examine solution).

On $1.5 \mathrm{ml}$ the received solution and the standard solutions 1 , 2 and 3 alternately chromatographed on the gas chromatograph supplied with the device of automatic input of tests with the ardent and ionization detector, receiving not less than 5 
chromatograms each of solutions, in the following conditions:

- column capillary quartz, $50 \mathrm{~m}$ x $0.32 \mathrm{~mm}$ in size with the put layer of a motionless phase - FFAP, thickness of a layer of $1 \mathrm{~mm}$ meeting requirements of the test «Check of Suitability of chromatography System»;

- temperature of a column is programmed from $40^{\circ} \mathrm{C}$ (a delay of $3 \mathrm{~min}$ ) to $230^{\circ} \mathrm{C}$ (a delay of $10 \mathrm{~min}$ ) with a speed of $25^{\circ} \mathrm{C} / \mathrm{min}$;

- injector temperature $-230^{\circ} \mathrm{C}$, the mode with splitting of a stream in the ratio $20: 1$

- detector temperature $-270^{\circ} \mathrm{C}$;

- gas carrier speed (hydrogen or helium for a chromatography $P) 2.0 \mathrm{ml} / \mathrm{min}$.

The content of camphor ( $\beta$-pinene) $(\mathrm{X})$ in a preparation as a percentage is calculated by the formula (3):

$$
\mathrm{X}=\left(\mathrm{S}_{1} \cdot \mathrm{m}_{0} \cdot 1 \cdot 50 \cdot 1 \cdot \mathrm{P} \cdot 100\right) /\left(\mathrm{S}_{0} \mathrm{~m} \cdot 50 \cdot 100 \cdot 100\right)
$$

where $S_{1}$ - average value of the areas of peaks of camphor ( $\beta$-pinene) calculated from the chromatograms of the examinee solution;

$\mathrm{S}_{0}$ - average value of the areas of peaks of camphor $(\beta-$ pinene) calculated from the chromatograms of the standard solution;

$\mathrm{m}_{0}$ - mass of the hinge plate of the standard sample (SS) of camphor ( $\beta$-pinene), $g$;

$\mathrm{m}$ - mass of the hinge plate of extract, $\mathrm{g}$;

$\mathrm{P}$ - content of camphor ( $\beta$-pinene) in SS, $\%$.

The content of camphor in $1 \mathrm{~g}$ of extract made $2.471 \%, \beta$ pinene in $1 \mathrm{~g}$ of extract $-2.39 \%$.

The test of camphor and $\beta$-pinene was carried out in tablets by gas chromatography.

$6.6 \mathrm{~g}$ (precise linkage) powder of crushed tablets transferred into a volumetric flask with a capacity of $50 \mathrm{ml}$, add $40 \mathrm{ml}$ of $96 \%$ alcohol $P$. The resulting solution is incubated on ULTRASONIC bath for $5 \mathrm{~min}$, cooled and made up to the mark with the same solvent, stirred and then filtered through the filter red ribbon (examinee solution).
$3 \mu \mathrm{l}$ the received solution and the standard solutions 1,2 alternately is chromatographed on the gas chromatograph which is equipped with the device of automatic input of tests with the ardent and ionization detector, receiving not less than 5 chromatograms each of solutions, in the following conditions:

- quartz capillary column, the size of $50 \mathrm{~m} \times 0.32 \mathrm{~mm}$ coated with a layer of stationary phase - FFAP, thickness $1 \mathrm{~mm}$, satisfying the requirements of the test, «Check the suitability of the chromatographic system»;

- column temperature is programmed from $40^{\circ} \mathrm{C}(3$ minutes delay) to $230^{\circ} \mathrm{C}$ (delayed $10 \mathrm{~min}$ ) at a speed of $25^{\circ} \mathrm{C} / \mathrm{min}$;

- injector temperature $-230^{\circ} \mathrm{C}$, with splitting of the flow regime in the ratio $20: 1$;

- detector temperature $-270^{\circ} \mathrm{C}$;

- speed of the carrier gas (hydrogen or helium) - 2.0 $\mathrm{mL} / \mathrm{min}$.

The content of camphor, $\beta$-pinene $(\mathrm{X})$ in the drug, in $\mathrm{mg}$, in terms of camphor or $\beta$-pinene, in average mass of the tablet is calculated by the formula (4):

$$
\mathrm{X}=\left(\mathrm{S}_{1} \cdot \mathrm{m}_{0} \cdot 50 \cdot 1 \cdot \mathrm{P} \cdot 1000 \cdot \mathrm{b}\right) /\left(\mathrm{S}_{0} \mathrm{~m} \cdot 50 \cdot 50 \cdot 100\right)
$$

where $S_{1}$ - average value of the squares of the peaks of camphor, $\beta$-pinene was calculated from the chromatograms of the examinee solution;

$\mathrm{S}_{0}$ - mean value of areas of peaks of camphor, $\beta$-pinene was calculated from the chromatograms of the standard solution;

$\mathrm{m}_{0}$ - sample weight standard sample (SS) camphor, $\beta$ pinene, $\mathrm{g}$;

$\mathrm{m}$ - mass of the drug sample, $\mathrm{g}$;

$\mathrm{P}$ - content of camphor, $\beta$-pinene in SS, \%;

$\mathrm{b}$ - average mass of the tablets.

The results of quantitative determination of camphor in tablets are shown in table 3 and metrological characteristics of the average result are shown in table 4 .

Table 3. The results of quantitative determination of camphor in tablets.

\begin{tabular}{llll}
\hline № & The mass of sample, $\mathbf{g}$ & The mean value of peak areas, $\mathbf{S}_{\mathbf{1}}$ & The content of camphor, mg \\
\hline 1 & 6.6004 & 1625.21 & 1.07 \\
2 & 6.6013 & 1503.90 & 0.99 \\
3 & 6.5989 & 1579.28 & 1.04 \\
4 & 6.6005 & 1427.78 & 0.94 \\
5 & 6.5978 & 1381.64 & 0.91 \\
6 & 6.6006 & 1473.37 & 0.97 \\
\hline
\end{tabular}

Notes: $\mathrm{S}_{0}=1373.82, \mathrm{~m}_{\mathrm{av}}-0.597$

Table 4. Metrological characteristics of the average result, $n=6$.

\begin{tabular}{llllllll}
\hline Found camphor, $\mathbf{m g}$ & $\mathbf{X}_{\mathbf{a v}, \mathbf{m g}}$ & $\mathbf{S}^{\mathbf{2}}$ & $\mathbf{S}$ & $\mathbf{P}, \mathbf{\%}$ & $\mathbf{T}(\mathbf{p}, \mathbf{v})$ & $\Delta \mathbf{X}_{\mathbf{a v}}$ & $\mathbf{E}_{\mathbf{a v}}, \boldsymbol{\%}$ \\
\hline 1.07 & & & & & & & \\
0.99 & & & & & & & \\
1.04 & 0.98 & 0.0036 & 0.0602 & 95 & 2.57 & & \\
0.94 & & & & & & & \\
0.91 & & & & & & & \\
0.97 & & & & & & & \\
\hline
\end{tabular}

The results of quantitative determination of $\beta$-pinene in tablets are shown in table 5 and metrological characteristics of the average result are shown in table 6. 
Table 5. The results of quantitative determination of $\beta$-pinene in tablets.

\begin{tabular}{llll}
\hline № & The mass of sample, $\mathbf{g}$ & The mean value of peak areas, $\mathbf{S}_{\mathbf{1}}$ & The content of camphor, mg \\
\hline 1 & 6.6004 & 143.99 & 0.91 \\
2 & 6.6013 & 155.09 & 0.98 \\
3 & 6.5989 & 150.29 & 0.95 \\
4 & 6.6005 & 150.32 & 0.93 \\
5 & 6.5978 & 143.94 & 0.91 \\
6 & 6.6006 & 153.49 & 0.97 \\
\hline
\end{tabular}

Notes: $\mathrm{S}_{0}=143.12, \mathrm{~m}_{\mathrm{av}}-0.597$

Table 6. Metrological characteristics of the average result, $n=6$.

\begin{tabular}{|c|c|c|c|c|c|c|c|}
\hline Found $\beta$-pinene, mg & $X_{\mathrm{av}}, \mathrm{mg}$ & $S^{2}$ & $\mathbf{S}$ & $\mathbf{P}, \%$ & $T(p, v)$ & $\Delta \mathbf{X}_{\mathrm{av}}$ & $\varepsilon_{\mathrm{av}}, \%$ \\
\hline 0.91 & \multirow{5}{*}{0.94} & \multirow{5}{*}{0.0009} & \multirow{5}{*}{0.0299} & \multirow{5}{*}{95} & \multirow{5}{*}{2.57} & \multirow{5}{*}{0.0128} & \multirow{5}{*}{1.36} \\
\hline 0.98 & & & & & & & \\
\hline $\begin{array}{l}0.95 \\
0.93\end{array}$ & & & & & & & \\
\hline 0.91 & & & & & & & \\
\hline 0.97 & & & & & & & \\
\hline
\end{tabular}

Thus, the content of camphor, $\beta$-pinene $(X)$ in the drug, in $\mathrm{mg}$ in terms of camphor or $\beta$-pinene, the average mass of the tablets comply with pharmacopoeia requirements of the draft PAND on tablets "Exkair".

\section{Discussion of Results}

On the basis of Association with limited opportunities of «Fito-Aromat» dense $\mathrm{CO}_{2}$-extracts from flowers of the Acorus Calamus rhizomes and Calendula officinalis were received. Receiving extracts were carried out in subcritical conditions on the extraction UUPE5L installation, according to the standard of the enterprise (ST 27658-1910-TOO-022011). As an estrogen liquid carbonic acid was used. Extraction parameters are set: pressure is 62 atm., temperature is $23-24^{\circ} \mathrm{C}$, time of extraction of $4 \mathrm{~h}$. The exit of extracts made $0.7-0.8 \%$.

Based on extracts designed composition of tablets:

thick extract of Acorus Calamus rhizomes (0.009 g), thick extract of flowers of Calendula officinalis $(0.005 \mathrm{~g})$; auxiliary substances - ascorbic acid $(0.005 \mathrm{~g})$, calcium stearate $(0.006$ $\mathrm{g})$, sugar powder $(0.517 \mathrm{~g})$, aerosil $(0.015 \mathrm{~g})$.

Confirmation of the quality of tablets "Exkair" was carried out in accordance with the requirements of the developed draft PAND. Quality evaluation of tablets was carried out in the following main indicators: identification and quantitative determination of carotenoids, camphor and pinene.

\section{Conclusions}

Receiving extracts was carried out in subcritical conditions according to the standard of the ST enterprise 27658-1910-TOO-02-2011. As an estrogen liquid carbonic acid was used. The component composition of extract of the Acorus calamus is revealed: camphor - not less than $0.1 \%$ in $1 \mathrm{~g}$ of extract; $\beta$-pinene - not less than $0.1 \%$ in $1 \mathrm{~g}$ of extract; borneol - in connection with the insignificant contents, its quantity isn't regulated. Based on extracts of rhizomes Calamus, Calendula flowers drug developed solid dosage forms - tablets, which are currently held comprehensive studies (chemical, physico-chemical, technological, and other non-clinical).

We developed methods for quantitative determination of the content of active substances (carotenoids), camphor and pinene in the tablet. Picked up an optimal ratio of herbal compositions, which form the basis of active components and auxiliary components, corresponding to the developed composition of the combined pill "Exkair".

\section{References}

[1] State Pharmacopoeia of the Republic of Kazakhstan (SF) RK I, t. 1, 2.2.25.

[2] State Pharmacopoeia of the Republic of Kazakhstan (SF) RK I, t., 2.2.27.

[3] State Pharmacopoeia of the Republic of Kazakhstan (SF) RK I, t., 2.2.28.

[4] Kasyanov G. I., Mkhitaryants G. A. Sub - and supercritical $\mathrm{CO}_{2}$-extraction of valuable components from vegetable raw materials // Collection of materials of the international scientific and technical Internet conference "The Sub - and Supercritical Fluid Technologies in the Food Industry". Krasnodar: KubGTU, 2012. - P. 80-83.

[5] Ustenova G. O. Extraction by the liquefied gases. - Manual, Almaty: KazNMU, 2010. - 66 p.

[6] Kasyanov G. I. $\mathrm{CO}_{2}$-extracts. Production and application. Monograph: Under the editorship of the prof. Scherbakov V. G. - Krasnodar: Ecoinvestment, 2010. - 176 p.

[7] Ibadullayeva G. S., Pichkhadze G. M., Ustenova G. O., Dilbarkhanov R., Tikhonova S. A., Grudko V. A., Bevz N. Y., Yudina $\mathrm{Yu}$. V. The Chemical composition of $\mathrm{CO}_{2}$-extract of the Acorus marsh, received in subcritical conditions // The Chemical and pharmaceutical magazine. - M, 2015. - No. 5. P. 56-60. 
[8] Ibadullayeva G. S., Bochkhaeva A. K., Ustenova G. O., Datkhayev U. M., Sakipova Z. B., Tikhonova S. A., Grudko V. A., Bevz N. Y. Standardization of Calamus $\mathrm{CO}_{2}$-extract and study of individual fractions of herbal preparations // Life Science Journal. - 2014. - №11 (5s) // http://www // Life Science Journal. - 2014. - №11(2s). - P. 25-27.

[9] Shikov A. N., Makarov G. V., Ryzhenkov V. E. Vegetable oils and oil extracts: technology, standardization, properties. - M.: Publishing House. Home "Russian doctor". - 2004.

[10] Tinctures, extracts, elixirs and standardization / edited by Bagirova V. L. and A. V. Severtsev - St. P: Specialized Literature, 2001.

[11] Stasyeva Oksana Nikolaevna. Improvement of technology of production and application of $\mathrm{CO}_{2}$-extracts from vegetable raw materials: the dissertation... of candidate of technical sciences: 05.18.10. - Krasnodar, 2005. - 153 p.

[12] Savin, Vladimir Nikolayevich. The improving technology for obtaining valuable components from vegetative raw materials with environmentally safe physical methods: dissertation... of candidate of technical sciences: 05.18.01 Krasnodar, 2006. $163 \mathrm{p}$.

[13] Kasyanov G. I., Malashenko N. L., Silinskaya S. M. Technics and Technology of using carbon dioxide as the extracting medium // News of University. Food technology. 2014. - N. 4. - P. 6-9.

[14] Kasyanov G. I. Technics and Technology of using carbon dioxide in sub- and supercritical state // Bulletin of the Voronezh state University of engineering technologies. 2014. No. 1. - P. 130-135.

[15] Gavashelishvili, L. V. Development of composition and technology of lingual tablets containing chlorophyllipt thick extract and thyme liquid extract: the dissertation... of candidate of pharmaceutical sciences: 14.04.01 / Gavashelishvili Lali Vasilyevna; [a defence place: "Pyatigorsk state pharmaceutical academy"]. - Pyatigorsk, 2011. - 122 p.

[16] Development of the technology of granules of Linden extract, pills of extract hibiscus and rosehip extract: abstract of thesis... candidate of pharmaceutical sciences: 15.00.01 / Paleskin Anatoly Vladimirovich; [a defence place: St. Petersburg state chem.-pharmacist. acad.] - St. Petersburg, 2009. - 29 P.

[17] The draft of Provisional Analytic Normative Document (PAND) Extract of the Calamus.

[18] The draft of Provisional Analytic Normative Document (PAND) Extract of the Calendula. 